Cahiers $d u$ MONDE RUSSE

\section{Cahiers du monde russe}

Russie - Empire russe - Union soviétique et États indépendants

$50 / 4 \mid 2009$

Varia

\title{
Christoph Witzenrath, Cossacks and the Russian Empire, 1598-1725
}

\section{Anna Joukovskaia}

\section{OpenEdition}

Journals

Édition électronique

URL : https://journals.openedition.org/monderusse/7140

DOI : 10.4000/monderusse. 7140

ISSN : $1777-5388$

\section{Éditeur}

Éditions de l'EHESS

\section{Édition imprimée}

Date de publication : 15 décembre 2009

Pagination : 769-770

ISBN : 978-2-7132-2261-0

ISSN : $1252-6576$

Référence électronique

Anna Joukovskaia, «Christoph Witzenrath, Cossacks and the Russian Empire, 1598-1725 », Cahiers du monde russe [En ligne], 50/4 | 2009, mis en ligne le 12 janvier 2011, consulté le 03 septembre 2022. URL : http://journals.openedition.org/monderusse/7140 ; DOI : https://doi.org/10.4000/monderusse. 7140

Ce document a été généré automatiquement le 3 septembre 2022.

Tous droits réservés 


\title{
Christoph Witzenrath, Cossacks and the Russian Empire, 1598-1725
}

\author{
Anna Joukovskaia
}

\section{RÉFÉRENCE}

Christoph WITZENRATH, Cossacks and the Russian Empire, 1598-1725. Manipulation,

Rebellion and Expansion into Siberia. London - New York : Routledge, 2007,

$\mathrm{XII}+259 \mathrm{p}$. (Routledge Studies in the History of Russia and Eastern Europe)

1 Dans ce livre compact, à l'écriture dense, l'auteur propose des réponses complexes à des questions compliquées, et défie plus d'une fois l'historiographie existante. Son interprétation de la conquête sibérienne, menée par la Russie durant un long XVII ${ }^{\mathrm{e}}$ siècle, est fondée sur un vaste corpus de sources d'archives, ignorées ou négligées par les historiens jusqu'ici, et dont la consultation s'était révélée une entreprise ardue en raison d'une paléographie difficile et d'un mauvais état de conservation. L'auteur soumet ses sources à une analyse multidisciplinaire qui s'inspire de la sociologie des organisations, de la psychologie des groupes, de l'anthropologie culturelle et de la sociologie militaire. Le caractère pluridimensionnel de l'ouvrage, qui parcourt tout le chemin de l'étude de cas à la construction de concepts et de modèles, en fait une lecture enrichissante non seulement pour les spécialistes de la Russie, mais également pour les historiens du colonialisme occidental.

2 L'ouvrage est divisé en sept chapitres : "Introduction ", " The Cossack Group », "The Economics of Siberian Service », "Integration of the Trading Frontier: the Sovereign's Affair ", « Kormlenie and Bribery: Local Influence and Administration", "Local and Central Power in the Baikal Region 1689-1720», "Conclusion». L'enquête est représentative, car elle concerne des villes et des districts de taille, statut administratif et profil socio-économique différents, distribués sur un espace de près de dix millions de kilomètres carrés, de l'Ural au fleuve Lena : Barguzinsk, Enisejsk, Il'insk, Irkutsk, Kaban 'sk, Krasnojarsk, Narym, Nerčinsk, Selenginsk, Surgut, Tjumen', Tomsk, Udinsk, 
Verhotur'e, Jakutsk, et quelques autres. La majorité des sources proviennent des fonds du secrétariat de Sibérie, du secrétariat à la Guerre, et de la chancellerie de la ville d'Irkutsk (conservés au RGADA, Archives d'État des actes anciens de Moscou).

Deux questions principales sous-tendent l'analyse. En premier lieu, l'auteur démontre à nouveaux frais, contre la thèse traditionnelle du centralisme étatique - simplificatrice et tout simplement inexacte-, comment Moscou contrôlait une zone géographique distante (le voyage jusqu'à la Sibérie occidentale durait près d'un an), dotée d'une très faible infrastructure, alors qu'elle disposait d'un nombre strictement limité d'agents civils et militaires. En second lieu, il examine les moyens qui permettaient au gouvernement central de maintenir la loyauté des administrateurs locaux éloignés, faiblement rémunérés et soumis en permanence à la tentation d'abus de fonction.

Le pouvoir du tsar était représenté localement par deux forces principales qui se complétaient et s'opposaient tout à la fois: les voevody (gouverneurs), dirigeants administratifs et militaires des districts, nommés depuis Moscou pour des périodes limitées, et les cosaques de Sibérie, habitants locaux permanents, voire indigènes, organisés en corporations urbaines. Witzenrath multiplie les études de cas pour montrer comment la solidarité corporative des cosaques des différentes villes sibériennes se transformait par moments en une arme qui leur permettait de défendre efficacement leurs intérêts face aux directives du centre ou aux initiatives des gouverneurs, au-delà des privilèges formels qui leur étaient accordés et en l'absence d'un espace d'autonomie corporative officiellement reconnu.

5 Pour décrire le corporatisme spécifique des cosaques, l'auteur recourt à une notion exogène aux sources moscovites, le Personenverband, c'est-à-dire une association, ou alliance personnelle, entre certains membres d'une strate sociale donnée. Les Personenverbände, dans les différentes villes étudiées, constitueraient des forces capables de négocier efficacement les intérêts collectifs et individuels de leurs membres dans un jeu complexe entre le secrétariat de Sibérie, les gouverneurs locaux de différents niveaux et leurs chancelleries respectives.

6 Comme toute bonne étude, le livre de Witzenrath suggère des questions qui le dépassent et ouvre des pistes pour de futures recherches, dont une en particulier parait fondamentale. Si le Personenverband était véritablement une forme d'auto-organisation spécifique des cosaques en Sibérie, à quoi tenait cette spécificité ? Autrement dit, qu'estce qui distinguait les cosaques des mousquetaires ou des artilleurs qui cohabitaient avec eux dans les villes sibériennes et remplissaient essentiellement les mêmes fonctions? Certes, Witzenrath démontre d'une façon convaincante la réalité du corporatisme cosaque, mais on est en droit de supposer que, d'une part, son principe n'était pas unique et que, d'autre part, il pouvait fonctionner de façon conjoncturelle et non permanente. L'identité cosaque, qui apparaissait et s'exprimait si nettement lors de certains conflits examinés dans le livre, était-elle immuable, ou bien pouvait-elle s'effacer ou s'estomper à d'autres moments au profit de loyautés définies par des critères autres que le corporatisme cosaque ? Et si oui, ne serait-on pas en présence d'un phénomène général, concernant toute identité collective? 